\title{
Development and results of a questionnaire to measure carer satisfaction after stroke
}

\author{
Pandora Pound, Patrick Gompertz, Shah Ebrahim
}

\begin{abstract}
Study objective-To develop a carer satisfaction questionnaire for use as an outcome measure in stroke, to test the measure for reliability and validity, and to survey levels of carer satisfaction with services for stroke patients.
\end{abstract}

Design-Postal survey of carer satisfaction with stroke services was carried out using the questionnaire we developed and tested. Internal consistency was tested and construct validation was explored by examining correlations with other outcome measures (the Faces Scale, the Nottingham Health Profile, the short form of the Geriatric Depression Scale, and the patient's Barthel Index score).

Setting-Two adjacent districts in North East Thames Regional Health Authority.

Participants-A total of 103 carers were identified from 219 people who had survived a stroke to six months. During the pilot stage, six of seven carers who were invited to participated in in depth interviews and 15 of 23 carers $(65 \%)$ who were invited to completed the first draft of the questionnaire.

Main results-The questionnaire was divided into two sections, one on inpatient services (Carer Hospsat) and one on services after discharge (Carer Homesat). The questionnaire had construct validity, providing significant correlations with the Faces Scale (Carer Hospsat $r=0 \cdot 59, p<0 \cdot 00001$ and Carer Homesat $r=0.68, p<0.00001$ ), the patients' Barthel score (Carer Hospsat $r=0 \cdot 25, p=0 \cdot 01$ ), and the patients' Nottingham extended Activities of Daily Living (ADL) scale (Carer Hospsat $r=0.31, p=0.002)$. Internal consistency was high for both sections (Cronbach's alpha: Carer Hospsat 0.87, Carer Homesat 0.79). Most carers (77\%) were satisfied with the care their relative or friend received while in hospital, but only $39 \%$ were satisfied with services after discharge.

Conclusions-Carer satisfaction is an important outcome measure in stroke research. This study has shown that carers are dissatisfied with services after hospital discharge. Our questionnaire is valid, reliable, and sensitive and could be used to test interventions aimed at improving services.

f Epidemiol Community Health 1993; 47: 500-505

It has long been recognised that stroke affects profoundly both the patient and the family. ${ }^{1-3}$ It was found recently that only $6 \%$ of people who had had a stroke named someone other than family or friends as the main source of care ${ }^{4}$ most care for stroke patients is carried out informally by family or friends. Important work has identified what problems these carers encounter, ${ }^{25-8}$ what tasks they carry out, ${ }^{9} 10$ what services they receive to help them, ${ }^{3} 1112$ and how these relate to the patient's level of dependence, ${ }^{13}$ but until recently ${ }^{14}$ patients and carers have not been asked for their views on how to improve services. The importance of using patient, but not carer, satisfaction as an outcome measure is increasingly recognised. For a chronic illness such as stroke, in which carers occupy such a pivotal role, however, it is important to develop measures of carer satisfaction. The consensus statement by the King's Fund ${ }^{15}$ claimed, "the services (for stroke) that are provided in hospital, primary care and the community seem haphazard, fragmented, and poorly tailored to patients' needs ...". We hypothesized that carers' satisfaction with stroke services would be low. This paper describes the development of a carer satisfaction questionnaire and reports on the results we found in a group of carers for people who had had a stroke.

\section{Methods}

QUESTIONNAIRE DEVELOPMENT AND PILOTING The various stages of the development of the questionnaire are outlined in figure 1. The content was determined by interviews with carers and a search of the published reports. A sample of seven experienced carers of people with stroke was identified from the wards and six of these agreed to take part in the study. The carers comprised three spouses, one daughter, one friend, and one neighbour. All were identified as the person who was relied upon most for personal, practical, or emotional help. Five of the carers were women. Unstructured, tape recorded interviews were conducted in carers' homes two to three months after the people they were caring for had had their stroke. The "informal conversational interview" approach $^{16}$ was used, meaning that only the general topic of the interview was predetermined-what carers thought about the services that existed for people who had had a stroke. The open format aimed to encourage carers to raise their own concerns according to individual priorities. The interviews were then transcribed and subjected to content analysis. ${ }^{17}$

Both the published reports and the interviews indicated that discharge preparation and community support would be areas of concern to carers, but only the interviews suggested that the quality of inpatient care was also important. A 


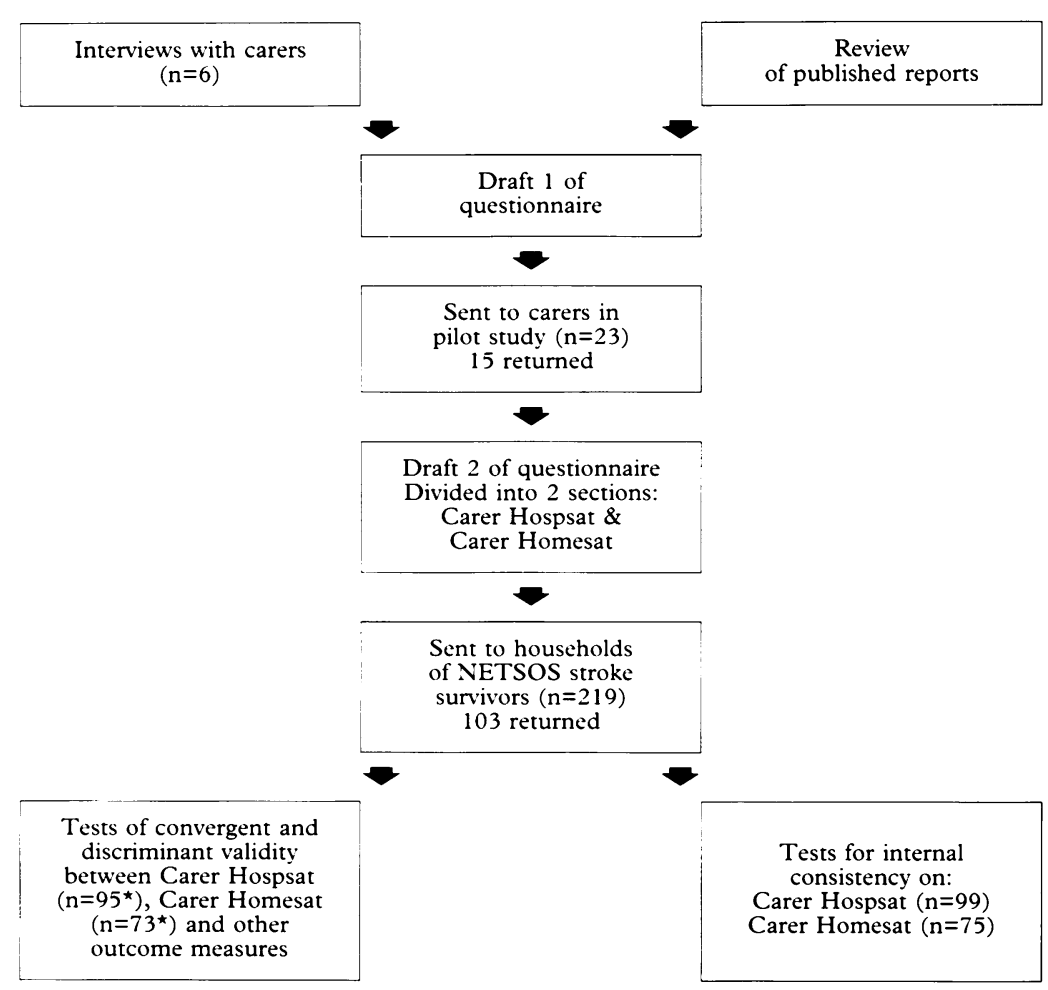

* The sample size varied for each correlation calculated. The figure in brackets shows the minimum. Individual sample sizes are recorded in table I. NETSOS=North East Thames Stroke Outcome Study.

Figure 1 Development of carer satisfaction questionnaire

questionnaire comprising nine statements was put together taking into account the results of the depth interviews and the search of published reports. The statements had response categories of "strongly agree", "agree", “disagree", or "strongly disagree". The questionnaire was piloted on a sample of 23 carers of patients whose names were taken from a consecutive register of stroke admissions to hospitals in a district in North East Thames Regional Health Authority. Questionnaires were sent only to households of survivors, six months after the stroke. The response rate after one mailing was $65 \%(n=15)$. All the questions were answered and the format seemed to have been well understood and acceptable to the respondents. The final version of the questionnaire (fig 2) was subsequently divided into two sections, one relating to inpatient care (Carer Hospsat) and the other to services after discharge (Carer Homesat). This was to facilitate analysis, allowing for the fact that some stroke survivors would still be in hospital six months after their stroke.

THE CARER SATISFACTION SURVEY

The carer satisfaction questionnaire was sent to the households of all six month survivors of the North East Thames Stroke Outcome Study (NETSOS) stroke register, together with a global question about satisfaction with the hospital in general (using the Faces Scale). ${ }^{18}$ Postal versions of the Nottingham Health Profile ${ }^{19}$ and the short form of the Geriatric Depression Scale ${ }^{20}$ were also sent, and the person relied upon most by the stroke survivor for personal, practical, or emotional help, was asked to complete them. The NETSOS register contains data on all 361 acute stroke admissions to the four major hospitals in two adjacent health districts in North East Thames between January 1991 and March 1992. (The stroke survivors themselves were also sent postal versions of the Nottingham Health Profile, the short form of the Geriatric Depression Scale, the Barthel Index ${ }^{21}$ the Nottingham extended activities of daily living scale, ${ }^{22}$ a patient satisfaction measure, and some demographic questions.)

\section{ANALYSIS OF RESULTS}

All data were analysed using SPSS/PC. A comparison was made of the age, Barthel score, Nottingham extended ADL score and housing tenure of the stroke survivors who identified carers who returned questionnaires, and those who did not. Internal consistency was tested for using Cronbach's alpha on the questionnaires returned from the satisfaction survey. Convergent and discriminant validity were explored by examining the correlation between the satisfaction questionnaire and the other carer (and some patient) outcome measures sent out at the same time. Correlation coefficients were calculated using Spearman's rank method.

The distributions of responses were compared for each item. Total scores were also derived by coding the response caetgories on a scale from 0 for "strongly disagree" to 3 for "strongly agree" and then summing these values to produce a total for each section.

\section{Results}

At six months, there were 219 surviving stroke patients on the NETSOS register. Of these, 103 identified carers who returned questionnaires. Only four $(4 \%)$ of these questionnaires were unusable. Of the remaining 99 carers, 24 rightly left the section on post-discharge services (Carer Homesat) uncompleted, because the stroke survivor had not yet been discharged. Ninety seven carers answered the global question about satisfaction with the hospital in general.

The carers comprised 50 spouses, 10 siblings, 29 daughters or sons, and six "other relations". Seven carers were not related to the stroke survivor and the status of the carer was not known in one case. Age was recorded for 96 of the carers, the mean being 60 years (SD 14). Seventy five of the carers $(73 \%)$ were women. For the purposes of analysis, the stroke survivors were categorised as dependent or independent (dependency being defined as less than or equal to 12 on the Barthel score). Using this system it was found that $48 \%$ of "independent" and 59\% of "dependent" stroke survivors identified a carer. Of the 37 "dependent" stroke survivors who did not identify a carer, $68 \%$ $(n=25)$ were in institutional care.

\section{VALIDITY AND RELIABILITY}

The Faces Scale presents seven faces, ranging from very happy to very sad, and in our case it asked people to sum up how satisfied they were with the hospital in general. We found a strong correlation between the total scores for Carer Hospsat and Carer Homesat and the scores obtained from the Faces Scale $(r=0.59$, $\mathrm{p}<0.00001$ and $\mathrm{r}=0.68, \mathrm{p}<0.00001$ respectively). No strong correlations were found between the total score for Carer Homesat and the carer's 

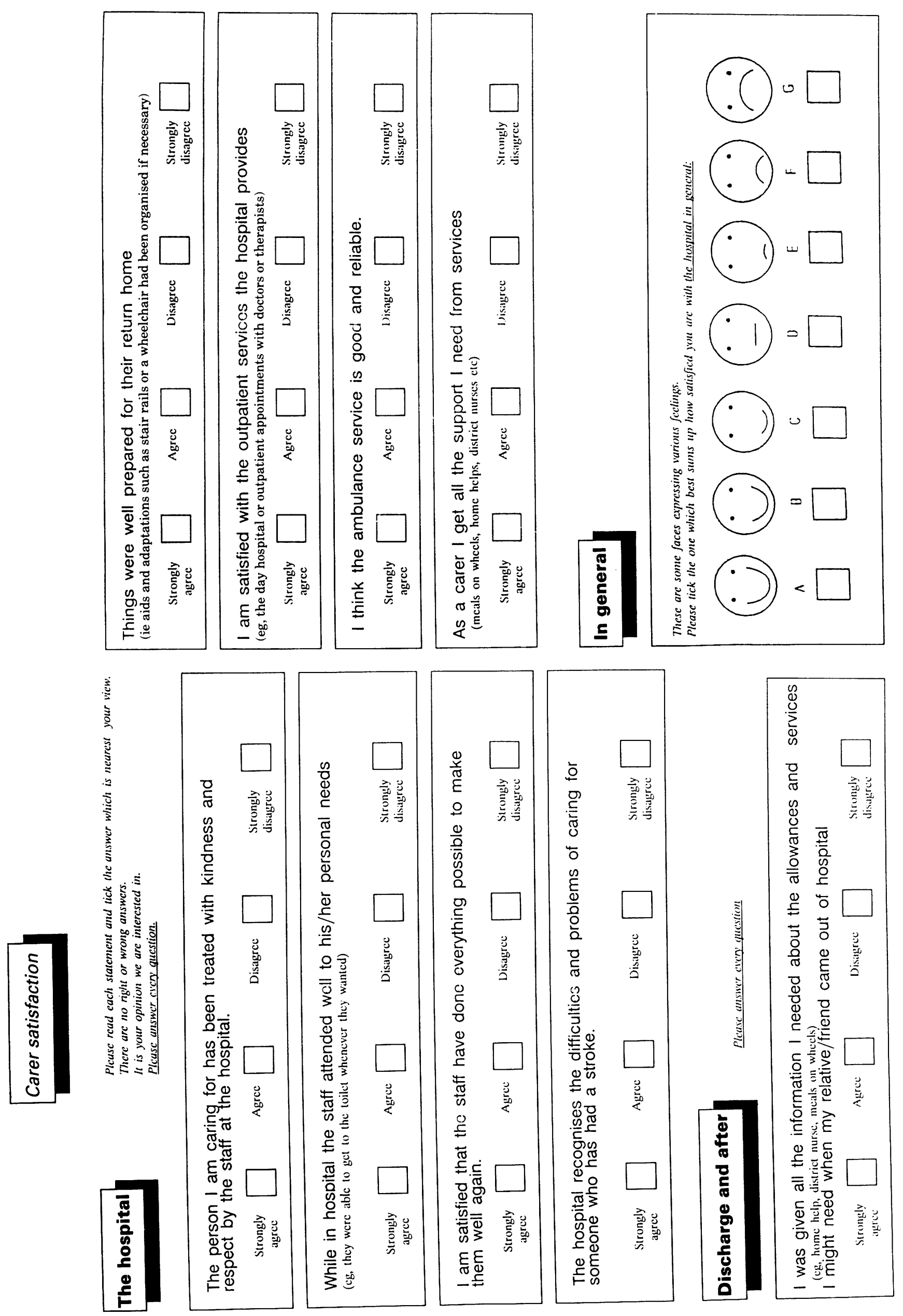
Geriatric Depression Score or Nottingham Health Profile. Apart from a negative correlation with the "sleep" subscale of the Nottingham Health Profile $(\mathrm{r}=-24, \mathrm{p}=0.02)$ there were no strong correlations between Carer Hospsat and the other carer outcomes. When Carer Hospsat and Carer Homesat were correlated with the patient's Barthel Index and Nottingham extended activities of daily living scores, positive correlations were found between Carer Hospsat and the Barthel Index $(r=0.25, p=0.01)$ and the Nottingham extended score $(r=0 \cdot 31, p=(0 \cdot 002)$. (See table I).

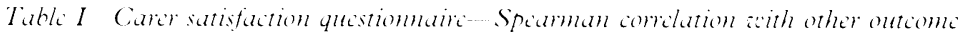
misiutias

\begin{tabular}{|c|c|c|c|c|c|c|}
\hline & \multicolumn{3}{|c|}{ Cure Hopsut } & \multicolumn{3}{|c|}{ Cunr Homlidu } \\
\hline & (a) molation & $r$ & Ni) & Complation & I & (Ni) \\
\hline 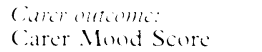 & $(1.13$ & 0.19 & 05 & $-1) \cdot 24$ & $(1)+5$ & \\
\hline Facen Scale & $(1.50)$ & $0.0(0)(0) 1$ & 97 & 0.08 & 0.00001 & $\frac{7}{7}$ \\
\hline NHP energy & $(1 \cdot 19$ & $0 \cdot(1) 0$ & 07 & -0.25 & 0.33 & $(74)$ \\
\hline NHP pain & 11.115 & 0.02 & $(97)$ & $-0 \cdot 10$ & 0.40 & (7) \\
\hline NHP cmotion & (1) 19 & 0.00 & $(97)$ & -0.23 & 0.05 & $(74)$ \\
\hline NHP scep & (1).2. & $(1 \cdot 0) 2$ & (97) & (1).21 & 0.07 & $(7+1)$ \\
\hline NHP acolal isolation & (1). 20 & $(1.0) 5$ & 97 & $-11 \cdot 14$ & 1). 23 & $(74)$ \\
\hline NHP physical mobility & 0.115 & 0.01 & 97 & 0.15 & 0.20 & 7. \\
\hline $\begin{array}{l}\text { Pation whome: } \\
\text { Barthel ADI. Index } \\
\text { Dotte extended }\end{array}$ & 11.25 & 0.01 & $(99)$ & 0.07 & (1). 50 & $(7)$ \\
\hline ADI Scalc & 0.31 & 0.0112 & 98 & 0.02 & 0.85 & $(75)$ \\
\hline
\end{tabular}

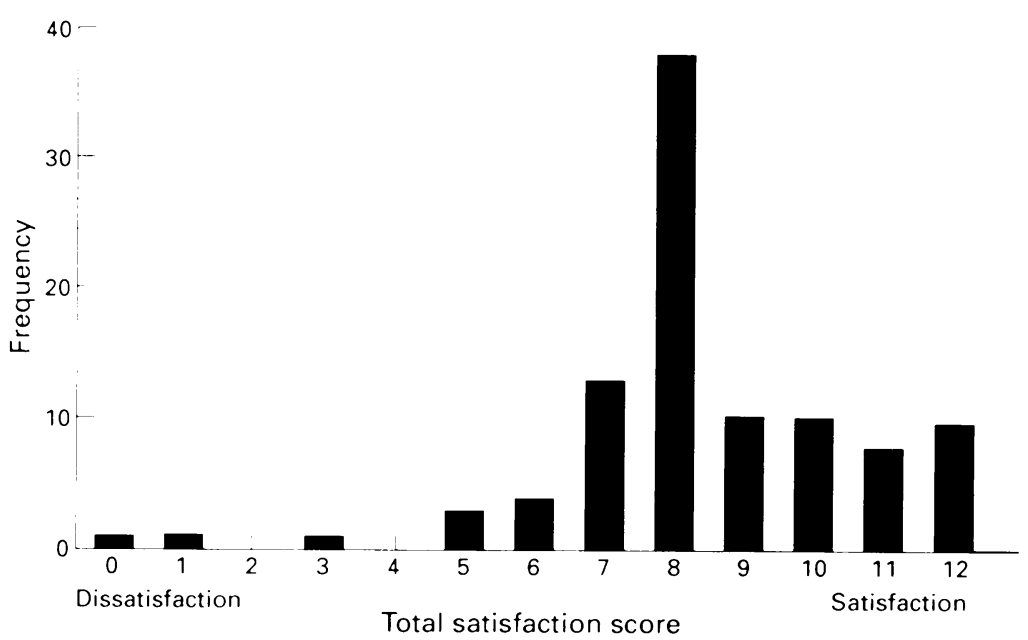

Figur 3 Distribution of toral satisfaction scores $(n=99)$ for hospital care after stroke

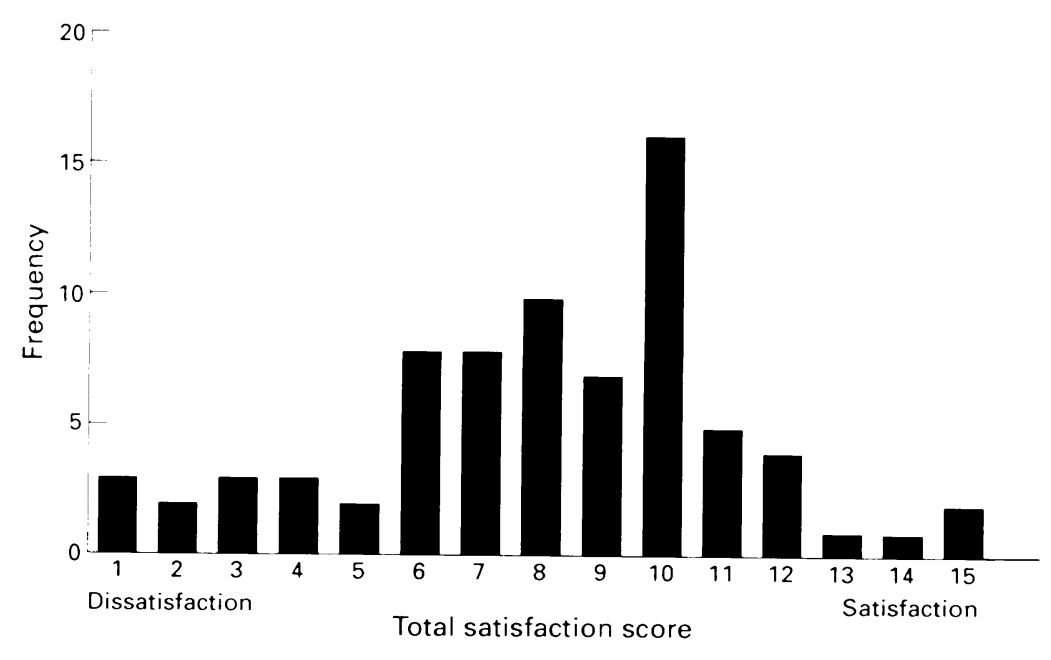

Figrue + Distribution of total satisfaction sores $(n=75)$ after discharge from hospital
Cronbach's alpha was 0.87 for Carer Hospsat and 0.79 for Carer Homesat $(\mathrm{n}=99$ and 75 respectively).

SATISFACTION WITH STROKE SERICES

The first section, Carer Hospsat, was completed by 99 people. It consisted of four questions; the lowest possible score for this section was 0 and the highest 12 . The distribution of total scores for this section is shown in fig 3 . The mean score was $8 \cdot 4$. A score of 8 is equivalent to a person answering "agree" for each question, and is taken to indicate satisfaction with most aspects of care received. Seventy six carers were satisfied with the care their relative or friend had received in hospital, including 10 who were satisfied with every aspect of care received. Twenty three answered that they were dissatisfied with some aspect of the care their relative or friend received in hospital, and of these, three were dissatisfied with every aspect of care received.

Carer Homesat was completed by 75 people. In this section there were five questions, the lowest possible score being 0 and the highest 15 . The distribution of total scores for this section is shown in fig 4 . The mean was $8 \cdot 1$. A score of 10 is equivalent to a person answering "agree" to each question, again indicating satisfaction with most aspects of care received. Twenty nine carers came into this category. Forty six carers were dissatisfied with some aspect of the services their relative or friend had received since discharge, including 13 who were dissatisfied with every service.

In response to the overall question asked on the Faces Scale, "How satisfied are you with the hospital in general?" $76 \%$ chose one of the first three faces indicating satisfaction, $14 \%$ chose one of the last three faces indicating dissatisfaction and $10 \%$ chose the middle face $(n=97)$.

An examination of the responses to individual questions on Carer Hospsat (table II), shows that

Table II Carer satisfation questionnaire - responses to individual questions ("o)

\begin{tabular}{|c|c|c|c|c|}
\hline Qustions (summurisid) & $\begin{array}{l}\text { Strongly } \\
\text { agric }\end{array}$ & Aglic & Disagrie & $\begin{array}{l}\text { Seromgly } \\
\text { disugrou }\end{array}$ \\
\hline Carer Hospiat $(n=99)$ : & & & & \\
\hline $\begin{array}{l}\text { Treated with kindness } \\
\text { Staff attended to needs }\end{array}$ & $\begin{array}{l}26 \\
22\end{array}$ & $\begin{array}{l}66 \\
69\end{array}$ & $\begin{array}{l}0 \\
0\end{array}$ & $\frac{1}{3}$ \\
\hline Staff done all they can & 30 & 60 & 8 & 2 \\
\hline Recognises difficulties & 18 & 06 & 14 & 2 \\
\hline$r$ Homciat $n=-5)$ & & & & \\
\hline Wutpaticnts satisfactory & 11 & 65 & 10 & 8 \\
\hline en infor re benctits & 11 & 14 & 28 & 17 \\
\hline ad discharge prep & 9 & 49 & 31 & 11 \\
\hline od carer support & 8 & 53 & 23 & 10 \\
\hline ulance reliable & 19 & 47 & 20 & 15 \\
\hline
\end{tabular}

most carers were satisfied that the person they were caring for had been treated with kindness and respect by the hospital staff $\left(92^{\prime \prime} " 1\right)$, that their personal needs had been well attended to $(91$ "0), that the staff had done everything possible to make them well again $(90 \%)$, and that the hospital recognised the difficulties and problems of caring for someone who has had a stroke $\left(84^{\circ} \%\right)$.

For Carer Homesat (table II), there were much lower levels of satisfaction, the lowest was with information given about allowances and services needed after discharge $(55 \%)$, followed by the provision of aids and adaptations $(58 \%)$, carer domiciliary support $(61 \%)$, the ambulance service $\left(66^{\circ} \%\right)$, and finally, the outpatient services $\left(7 t^{\prime \prime}{ }_{11}\right)$. 


\section{Discussion}

RESPONSE RATE

It is impossible to know the true response rate for the carer satisfaction questionnaire since the size of the denominator (the number of stroke survivors who had carers) was not known in advance. That only $47 \%$ of stroke survivors identified a carer who then returned a questionnaire is a little disappointing, since one would expect the number to be higher in a sample of stroke survivors. However, it is clear that of those people defined as dependent (and presumably therefore having a carer), most identified a carer who then returned a questionnaire. Of those dependent people who did not identify a carer, $68 \%$ were in institutional care and would have found it difficult to identify a non-professional carer.

Nevertheless, there were still a small number $(n=12)$ of dependent stroke survivors living at home, whose carers (assuming they had one) did not return questionnaires. It is possible that the response rate could have been improved by identifying the carers beforehand so that questionnaires could have been addressed directly to them, and by name, rather than going via the stroke survivor. The latter, having already completed a large number of their own questionnaires, may have lacked the motivation to encourage completion of the carer questionnaires. It would not seem that the satisfaction questionnaire itself was offputting-that only $4 \% \quad(n=4)$ of the returned questionnaires were unusable suggests that the questionnaire is easy to use.

\section{VALIDITY AND RELIABILITY}

Exploratory interviewing is recommended in the design of questionnaires. ${ }^{23}$ Its addition to other forms of selecting questions, such as a search of published reports, increases confidence in the content validity of the questionnaire.

The total score for Carer Hospsat and Carer Homesat correlates strongly with the Faces Scale, providing evidence of convergent validity for the questionnaire and also suggesting that it is valid to derive an overall satisfaction score for each section. The general lack of correlation with the Geriatric Depression Score or the Nottingham Health Profile suggests that the questionnaire is measuring an independent dimension of experience, and thus has discriminant validity. The finding that the less disabled the patient was, the more satisfied the carer was with hospital care, is what one would expect and therefore provides evidence of construct validity for the questionnaire.

Internal consistency was high, implying that the questionnaire is reliable. However, test-retest reliability has yet to be explored.

RANGE OF RESPONSES

The level of dissatisfaction uncovered in Carer Homesat would suggest that the questionnaire has managed to avoid producing response acquiescence, given that satisfaction surveys generally uncover high levels of satisfaction with health care. $^{24}$

CARER'S SATISFACTION WITH STROKE SERVICES It is encouraging that most of carers were satisfied with the care their relative or friend received while in hospital, and particularly pleasing that $84 \%$ felt that there was recognition within the hospital of the difficulties and problems of caring for someone who has had a stroke. However, carers' satisfaction levels plummetted when it came to services related to discharge and after. Using the total score, $61 \%$ of carers were dissatisfied with some aspect of the services their relative or friend had received since discharge. It seems that the benefits gained while in hospital are in danger of being negated by the experience of services after discharge, as has been suggested elsewhere. ${ }^{6}$

Greatest dissatisfaction was elicited in response to the questions which asked about the provision of information on allowances and services needed after discharge $(45 \%)$, the provision of aids and adaptations (42\%) and carer domiciliary support $(39 \%)$. Several authors ${ }^{691214}$ have argued that it is discharge preparation, (particularly the speed and efficiency with which aids and adaptations are provided, and the accessibility of information about rights and entitlements) and services in the community that are in the greatest need of improvement. As long ago as 1976 Isaacs et al ${ }^{3}$ found that many stroke patients and carers lacked necessary health and social services in the community, and that information about rights to financial benefits and improved housing was not easily accessible. It is depressing that almost 20 years later, carers are reporting difficulties in the same areas.

Some studies have investigated the emotional strain experienced by carers and there seems to be evidence that carers of people with stroke have high levels of depression when compared with the general population. ${ }^{132526}$ However, the reasons for this depression and the route to its alleviation are not immediately clear. ${ }^{27}$ The only study so far to have asked patients and carers what they thought would lead to a better outcome found that of a group of 30 patients and carers, 14 suggested better support after hospital discharge (including "counselling"), 13 wanted more information about the illness and available resources, and 13 suggested more practical help, as opposed to only five people who advocated access to a stroke club. ${ }^{14}$ There is a vogue among stroke researchers to advocate counselling or self help groups as a means of reducing the difficulties faced by carers. There is a lack of evidence of the effectiveness of these measures; moreover it is not clear exactly what each of these measures mean. To one person, "counselling" might mean the provision of practical information while to another it might suggest an emotionally therapeutic encounter. The activities and roles of stroke clubs and carer support groups also vary greatly. Finally, the acceptability and relevance of interventions are likely to differ according to social, cultural, economic, and educational background. Among the working class carers who were interviewed for our pilot study there seemed to be little enthusiasm for carer support groups. One of them put it this way:

"They want me to go to one of these group things to listen to other people who have these complaints and that, but I think to myself, I know exactly what is going to happen, why do I want to listen to other people? I mean I'm surrounded by it all the time, I know what's going on." 
Moreover, in the main study, while $84 \%$ of carers were satisfied that the hospital recognised the difficulties and problems of caring for someone with a stroke, only $61 \%$ were satisfied with the practical support they got from the health and social services such as home helps, district nurses, meals on wheels, and so on.

It is likely that carers of people with stroke need a combination of practical and "emotional" support. There is a need to evaluate different interventions, and if progress is to be made much work needs to go into clarifying exactly what each one means. "Social support", for example, is also an ambiguous term. Finally, the choice of outcome measure is important. A carer satisfaction questionnaire addresses carers directly and provides information on the effectiveness and acceptability of services for them. Our instrument is able to distinguish between different aspects of the service and thereby highlight areas in need of attention.

1 Editorial Stroke and the Family. BMIf 1974; 4: 122

2 Mykyta LJ, Bowling JH, Nelson DA, Lloyd EJ. Caring for relatives of stroke patients. Age Ageing 1976; 5: 87-90.

3 Isaacs B, Neville Y, Rushford I. The stricken: the social consequences of stroke. Age Ageing 1976; 5: 188-192.

4 Anderson R. The aftermath of stroke. Cambridge: Cambridge University: Press, 1992.

5 Brocklchurst JC, Morris P, Andrews K, Richards B, Laycock P. Social effects of stroke. Soc Sit Med 1981;15A: 35-9. 6. Field D. Cordle CJ, Bowman GS. Coping with stroke at Field D, Cordle CJ, Bowman GS. Coping with stroke at
home. Intemational Rehabilitation. Ifedicine 1983; 5: 96-100.

7 Anderson R. The quality of life of stroke patients and their carers. In: Anderson R, Bury M, eds. I.icing with chronic carers. In: Anderson $\mathrm{R}$, Bury $\mathrm{M}$, eds. Licing with chromic
illnes: the experience of patients and their families. London: illness: the experience of

8 McLean J, Roper-Hall A, Maver P, Main A. Service needs of stroke survivors and their informal carers: a pilot study. $f$ Adr Nurs 1991; 16: 559-6-

Ebrahim S, Nouri F. Caring for stroke patients at home. International Rehabilitation Medicine 1986; 8: 1713.
10 Anderson $\mathrm{R}$. The contribution of informal care to the management of stroke. Int Disabil Stud 1988; 10: 107-37.

11 Legh-Smith J, W'ade DT, Langton Hewer R. Services for Stroke Patients One Year After Stroke. $\mathcal{f}$ Epidemiol Stroke Patients One Year After

12 Ebrahim S, Barer D, Nouri F. An audit of follow-up services for stroke patients after discharge from hospital. Int Disabil Siud 1987; 9: 103-5.

13 Greveson GC, Gray CS, French JM, James OFW. Longterm outcome for patients and carers following hospital admission for stroke. Age Ageing 1991; 20: 337-44.

14 Greveson G. Improving long term outcome after stroke-the views of patients and carers. Health Trends 1991;23: 161-2.

5 King's Fund Consensus Statement Treatment of stroke. B.117 1988; 297: 126-8.

16 Patton MQ. Hot to use qualitatice methods in exaluation. London: Sage Publications, 1987.

17 Guba EG. Toceard a methodology of naturalistic enquiry in ciducational craluation. CSE Monograph Series in Evaluation no 8. Los Angeles: Center for the Study of Evaluation, 1978

18 Andrews F.M and Withey SB. Social indicators of aicll-being: Americans' perceptions of life quality. New York: Plenum, 976.

19 Hunt SM, McEwen J, McKenna SP. Measuring health status. London: Croom Helm, 1986.

20 Lum O, Brink TL, Yesavage JA, Heersetma P, Ade YM, Rose TL. Screening tests for geriatric depression. Clinical Girentolog:. 1982; 1: 37-43.

21 Mahoney FI, Barthel DW. Functional evaluation: the Barthel Index. Marrland State Medical foumal 1965; 14 $61-5$

22 Nouri FM, Lincoln NB. An extended activities of daily living index for stroke patients. Clinical Rehabilitation 1987; 1: 3015 .

23 Sheatslev PB. Questionnaire construction and item writing. In: Rossi P, Wright J, Anderson A, eds. Handbook of sure'v' In: Rossi P, W right J, Anderson A, eds. Hundh

24 Locker D, Dunt D. Theoretical and methodological issues in sociological studies of consumer satisfaction with medical sociological studies of consumer satis

25 Carnwath TC.II, Johnson DAW. Psychiatric morbidity among spouses of patients with stroke BMIf 1987; 294: among

26 Wade DT, Legh-Smith J, Langton-Hewer R. Effects of living with and looking after survivors of a stroke. BLIF 1986;293: $+18-20$

27 Thompson SC, Bundek NI, Sobolew-Shubin A. The caregivers of stroke patients: an investigation of factors associated with depression. Foumal of Applied Social Psichologv 1990; 20(2): 114-29. 